This item was submitted to Loughborough's Research Repository by the author.

Items in Figshare are protected by copyright, with all rights reserved, unless otherwise indicated.

\title{
Low birthweight prevalence among Spanish women during the economic crisis: differences by parity
}

PLEASE CITE THE PUBLISHED VERSION

https://doi.org/10.1080/03014460.2020.1727010

\section{PUBLISHER}

Taylor and Francis

\section{VERSION}

AM (Accepted Manuscript)

\section{PUBLISHER STATEMENT}

This is an Accepted Manuscript of an article published by Taylor \& Francis in Annals of Human Biology on 10 Mar 20, available online: https://doi.org/10.1080/03014460.2020.1727010

\section{LICENCE}

CC BY-NC-ND 4.0

\section{REPOSITORY RECORD}

Terán, JM, S Juárez, C Bernis, Barry Bogin, and C Varea. 2020. "Low Birthweight Prevalence Among Spanish Women During the Economic Crisis: Differences by Parity”. Loughborough University. https://hdl.handle.net/2134/13237955.v2. 
Low birthweight prevalence among Spanish women during the economic crisis: Differences by parity

José Manuel TERÁN ${ }^{1}$, Sol JUÁREZ ${ }^{2}$, Cristina BERNIS ${ }^{1}$, Barry BOGIN³ ${ }^{3}$, Carlos VAREA ${ }^{1}$.

1. Department of Biology. Faculty of Sciences. Autonomous University of Madrid. Madrid, Spain.

2. Centre for Health Equity Studies (CHESS). Stockholm University / Karolinska Institute. Stockholm, Sweden.

3. School of Sports. Exercise \& Health Sciences. Loughborough University. Loughborough, England.

\section{Abstract}

Objective. To evaluate the trends in low birthweight (LBW) in Spain by parity during the 1996-2016 period. Method. Using data from the National Vital Statistics, joinpoint regression analysis was used to identify the timing of significant changes in the prevalence of LBW. The maternal-foetal characteristics as well unadjusted and adjusted relative risk (RR) of being born with LBW were compared between the established time periods. Results. The prevalence of LBW among live births to primiparous Spanish mothers increased from $5.1 \%$ to $6.87 \%$ in 2008 and then stabilized at maximum values, while among live births to multiparous mothers LBW increased from $4 \%$ to a maximum of $5.20 \%$ and then significantly reduced. Conclusions. There was a differential effect of the economic crisis on LBW according to parity, the negative impact being higher and more sustained among primiparous mothers. There may have been a social selection among mothers for pregnancies among those with lowest risks for LBW, more intense among multiparous mothers.

Key words: Maternal profile, Austerity, Psycho-social stress, Joinpoint regression analysis, Spain 


\section{Introduction}

The economic crisis which started in the USA in 2007 has had an unequal impact on the health of European populations, worse in those countries which adopted austerity measures and reduced social protection. ${ }^{1}$ As regards perinatal health, careful epidemiological analysis of countries that implemented more severe austerity measures reported an increase in the prevalence of low birthweight (LBW), confirming preliminary studies. $^{2}$

In the Spanish population a general and immediate increase has been described in the prevalence of intrauterine growth restriction following the outset of the crisis, ${ }^{3,4}$ as well as a rise in disparities in LBW by mother's education level. ${ }^{5,6}$ These results suggest that the economic recession affected perinatal health both by an increase in psycho-social stress and by the deterioration of material conditions. ${ }^{7}$ In Varea et al., (2016) (3) we presented an analysis of the impact of the economic crisis on foetal growth in Spain during the period 2003-2012, considering both maternal-foetal variables and macroeconomic indicators. The aim of the present study is to: 1) analyse trends in LBW by parity and 2) in the context of a wider time frame, from 1996 to 2016 in Spain to better understand the impact of the crisis. Prior studies conducted in the Spanish context suggest that the economic crisis might influence fertility decisions among women with a low socioeconomic position (measured by education) [Ramiro-Fariñas et al., 2017]. Given that the risk of LBW is socially patterned, the actual effect of the economic crisis on LBW can be diluted due to a social selection toward childbearing. We hypothesise that such a selection could influence primiparous and multiparous differently as, under equal social conditions, women who have children might be more prone to stop or delay childbearing.

\section{Methods}

The prevalence (\%) and relative risk (RR) of LBW in live births to Spanish mothers was analysed using data from the National Vital Statistics (NVS) between 1996 (the first year that mother's nationality was registered in the National Statistics) and 2016. The sample 
analysed corresponds to 6356688 live births. As in other high-income countries, delayed maternity in Spain is linked to a greater use of assisted delivery techniques and the resulting increase in multiple pregnancies (8). Because birthweight is often reduced in multiple pregnancies, the analyses were limited to single births to Spanish mothers. We excluded immigrant mothers. The three main groups of immigrant mothers in Spain, from Latin-America, the Maghreb, and Eastern Europe, have very different lifestyles and reproductive profiles [Bernis et al. 2013], requiring their own specific analysis on recent trends in birth outcomes Immigrant mothers comprised 1.64\% ( $n=104256)$ of the total sample. With or without the excluded migrant mothers, missing data were distributed randomly. The maternal-foetal variables considered are those included in the two versions of birth certificates valid for the period under study (those of 1996-2006 and 2007 onwards). These are the same a data sources assessed in previous studies [3, 5, 6, $8,10]$. Analyses have been stratified by parity, 'Primiparous' and 'Multiparous', and according to birthweight, LBW $=<2,500$ grams and 'Normal', as described by Terán et al. (2017)..$^{8}$ Most of the women (37.13\%) in the 'Multiparous' group had two live births.

By means of the Joinpoint regression program version $4.6 .0 .0^{9}$ we identified the years when the trend in prevalence of LBW changed significantly between 1996 and 2016. This program uses permutation analyses to fit a series of straight lines on a logarithmic scale to estimate annual per cent change $(\mathrm{APC}+/-95 \% \mathrm{Cl})$ and if the change in trend of the prevalence of LBW for each identified period is significant or not.

We also estimated the global unadjusted and adjusted relative risk (RR) of being born with LBW for each of the significantly different periods established by the Joinpoint regression analysis. Covariates considered were sex of the newborn, gestational age, age at childbirth, maternal and paternal occupation, and marital status.

\section{Results}

Figure 1 (see also Table $1 \mathrm{~A}$ in the Annex) shows the models obtained from joinpoint regression analysis for the temporal trends in the prevalence of LBW. For live births to primiparous mothers, 2009 was the year of inflection, showing a significant increase in the prevalence of LBW between 1996-2009 (APC=1.76, 95\% IC: 1.33, 2.20), reaching a 
maximum value of $6.87 \%$ in 2008 and then stabilisation from $2009-2016$ (APC=0.06; 95\% IC:-0.94, 1.07). For live births to multiparous women the cut-off point was established in 2008, with a significant increase in the prevalence of LBW between 1996-2008 to a maximum value of $5.20 \%$ ( $A P C=1.84,95 \%$ IC: $1.45,2.23)$ and a significant fall during the crisis (APC=-0.89, 95\% IC:-1.59, -0.18). For all live births considered, the model obtained shows a cut-off point in 2008 (1996-2008, APC=1.93, 95\% IC: 1.55, 2.31; 2008-2016, $A P C=-0.08,95 \%$ IC: $-0.73,0.57)$.

In comparison with the period 1996-2007, during the crisis and in both parity categories, women were predominantly professionals or admin workers (over 50\%), while housewives were halved (from about $32 \%$ to $17 \%$ ). The percentage of primiparous women 30 years old and older nearly doubled, as did the percentage of multiparous mothers 40 years old and older between the two time periods (Table 2).

Finally, after adjusting for confounding variables, the RR of having a live birth with LBW during the recession as compared with the previous period fell from 1.13 (95\% IC: 1.12, 1.14 ) to 1.07 (95\% IC: $1.06,1.08)$ for primiparous mothers, and from 1.08 (95\% IC: 1.07 , $1.10)$ to 1.04 (95\% IC: $1.03,1.06)$ for multiparous ones (annex Table A).

\section{Discussion}

Prior to the economic crisis in Spain there was a slight rising trend in fecundity, but from 2008 there was a continuous fall in births. With the 2008 crisis there was also an increase in the ages of first and successive births [3]. These trends also occurred in other European countries where the depth of the recession and institutional adjustments to economic austerity resulted in clear associations between reproductive behaviour and the economy. ${ }^{12}$ Following a period of economic prosperity, the Spanish population underwent from 2008 onwards an unexpected and prolonged period of psychological uncertainty and an effective increase in poverty and social inequality which affected almost all social sectors. ${ }^{13}$ Consequently, economic uncertainty, job insecurity and unemployment arising from the recession determined the postponement of, or definite decision not to undergo, first-time motherhood among Spanish women. The notable exception were those women with stable employment and guaranteed resources. ${ }^{14+R a m i r o-F a r i n ̃ a s ~ e t ~ a l ., ~} 2017$. Our results confirm that during the economic crisis there 
was a significant increase in births to both primiparous and multiparous women among highly qualified professionals and admin employees, and a substantial reduction of births to housewives and qualified workers (Table 1). The number of births to unskilled workers increased from before to after the crisis. This may be explained by the fact that the employment of women in non-qualified employment (associated with the industrial sector) remained more stable during the crisis than employment in the qualified sector (associated with small- and medium-sized business) or the service sector. In any case, LBW increased steadily among unskilled workers during the crisis, only surpassed by housewives, in both parity groups.

Quality of employment is correlated with greater stability and resources, and higher maternal education, a profile which affects positively birth outcome. ${ }^{3,6}$ Joinpoint regression analysis seems to confirm that the economic crisis determined a strong socioeconomic selection of women (or couples) who decided to be mothers for the first time or who decided to have another child. Joinpoint regression analysis show that the prevalence of LBW in live births to primiparous mothers stabilised during the crisis after rising to maximum levels for the temporal series studied (1996-2016), whereas for live births to multiparous mothers - who had a consistently lower prevalence of LBW-the LBW prevalence fell significantly to levels approaching the pre-crisis level. These results contrast with those for Portugal ${ }^{15}$, which show-also by means of joinpoint regression analysis-a continuous increase in LBW from 1999 among Portuguese nationals, with no evidence of maternal socio-economic selection during the crisis.

The trends in the prevalence of LBW shown also suggest that this social selection was more intense among women who were already mothers than among nulliparous ones, given that during the crisis the prevalence of LBW fell significantly among the former, whereas it increased and stabilised at maximum temporal levels among the latter. The unadjusted and adjusted RR values for either category of parity confirm this. The decrease in the prevalence of births with LBW among multiparous mothers, as well as the stabilisation among primiparous ones, are compatible with the idea that the decision to become mothers is more urgent for nulliparous women the closer they are to the biological limits of fecundity, which determines that they accept pregnancy even during a recession period and under acute psycho-social stress, whereas women who are 
already mothers choose to get pregnant again only if they enjoy job stability and sufficient resources, as their reproductive decision is less pressing ${ }^{12}$.

It is of public health importance to note that the present study shows a concentration of births to women from more privileged social backgrounds with better perinatal results. Taken on its own, this could mislead us to conclude that the economic crisis of 2007 had a limited or even positive effect on pregnancy outcome in our country. In the context of the full range of socio-economic and educational backgrounds this was not the case. Our previous analysis [6] confirmed that the prevalence of LBW increased between 2007 and 2015 for all categories of mothers, by employment and education, and that there was an increase in disparity among extreme socio-economic groups during the worst years of the recession, basically due to the mothers' educational level rather than to their occupation. Overall, the economic crisis had deleterious impact on pregnancy decisions and outcomes for most mothers.

\section{Disclosure statement}

The authors report no conflict of interest.

\section{Authorship contributions}

JM Terán and C Varea contributed to the design, which was reviewed and accepted by all authors. JM Terán contributed with data analysis. C. Varea wrote the first version of the article and all authors reviewed the different versions and performed a critical review with intellectual contributions until all agreed to approve the final version for publication.

\section{Funding}

None.

\section{Conflicts of interest}

None.

\section{References}


1. Parmar D, Stavropoulou C, Ioannidis JPA. Health outcomes during the 2008 financial crisis in Europe: systematic literature review. BMJ. 2016;354:i4588 Doi:10.1136/bmj.i4588.

2. Rajmil L, Taylor-Robinson D, Gunnlaugsson G, et al. Trends in social determinants of child health and perinatal outcomes in European countries 2005-2015 by level of austerity imposed by governments: a repeat cross-sectional analysis of routinely available data. BMJ Open. 2018;8:e022932. Doi: 10.1136/bmjopen-2018-022932.

3. Varea C, Terán JM, Bernis C, et al. Is the economic crisis affecting birth outcome in Spain? Evaluation of temporal trend in underweight at birth (2003-2012). Ann Hum Biol. 2016;43:169-82. Doi: 10.3109/03014460.2015.1131847.

4. Palència L, Puig-Barrachina $V$, Marí-dell'Olmo $M$, et al. Trends in small-forgestational age before and after the economic crisis in Spain. Eur J Public Health. 2018;28:325-7. Doi:10.1093/eurpub/cky017.

5. Juárez S, Revuelta-Eugercios BA, Ramiro-Fariñas $D$, et al. Maternal education and perinatal outcomes among Spanish women residing in Southern Spain (2001-2011). Matern Child Health J. 2014;18:1814-22. Doi:10.1007/s10995-013-1425-4.

6. Terán JM, Varea C, Juarez $\mathrm{S}$, et al. Social disparities in low birth weight among Spanish mothers during the economic crisis (2007-2015). Nutr Hosp. 2018;35:12941. Doi:10.20960/nh.2095.

7. Margerison-Zilko CE, Li Y, Luo Z. 2017. Economic Conditions During Pregnancy and Adverse Birth Outcomes Among Singleton Live Births in the United States, 19902013. Am J Epidemiol. 2017;186:1131-9. Doi: 10.1093/aje/kwx179.

8. Terán JM, Varea C, Bernis $C$, et al. New birthweight charts according to parity and type of delivery for the Spanish population. Gac Sanit. 2017;31:116-22. Doi:10.1016/j.gaceta.2016.09.016.

9. Joinpoint Regression Program, Version-4.6.0.0-April 2018; Statistical Methodology and Applications Branch, Surveillance Research Program, National Cancer Institute. https://surveillance.cancer.gov/joinpoint/

10. Varea C, Terán JM, Bernis C, et al. The impact of delayed maternity on foetal growth in Spain: An assessment by population attributable fraction. Women Birth. 2018;31:e190-6. doi: 10.1016/j. wombi.2017.09.004. Epub 2017 Sep 18. Doi: 10.1016/j.wombi.2017.09.004. 
11. Goldstein JR, Kreyenfeld M, Jasilioniene A, et al. Fertility reactions to the "Great Recession» in Europe: recent evidence from order-specific data. Demogr Res. 2013;29:85-104. Doi:10.4054/DemRes.2013.29.4.

12. OECD. Income inequality update: income inequality remains high in the face of weak recovery. OECD Publishing; 2016.

13. Vidal-Coso E, Miret-Gamundi P. Características de las madres primerizas y de los padres primerizos en la España del siglo XXI. REIS: Revista Española de Investigaciones Sociológicas. 2017;160:115-38. Doi:10.5477/cis/reis.160.115.

14. Kana MA, Correia S, Peleteiro B, et al. Impact of the global financial crisis on low birth weight in Portugal: a time-trend analysis. BMJ Glob Health. 2017;2:e000147. Doi:10.1136/bmjgh-2016-000147.

Bernis C, Varea C, Bogin B, González-González A. 2013. Labor management and mode of delivery among migrant and Spanish women: does the variability reflect differences in obstetric decisions according to ethnic origin? Matern Child Health J 17:918-927. DOI***

Ramiro-Farinas D, Viciana-Fernández FJ, Ferández, Montañez V. 2017. Will highly educated women have more children in the future? In Southern Europe, it will largely depend on labour market conditions. Vienna Yearbook of Population Research 15: 4954. DOI: 10.1553/populationyearbook2017s049 
Figure 1. Trends in low birthweight prevalence by parity and total (Spanish mothers, live single births, 1996-2016)

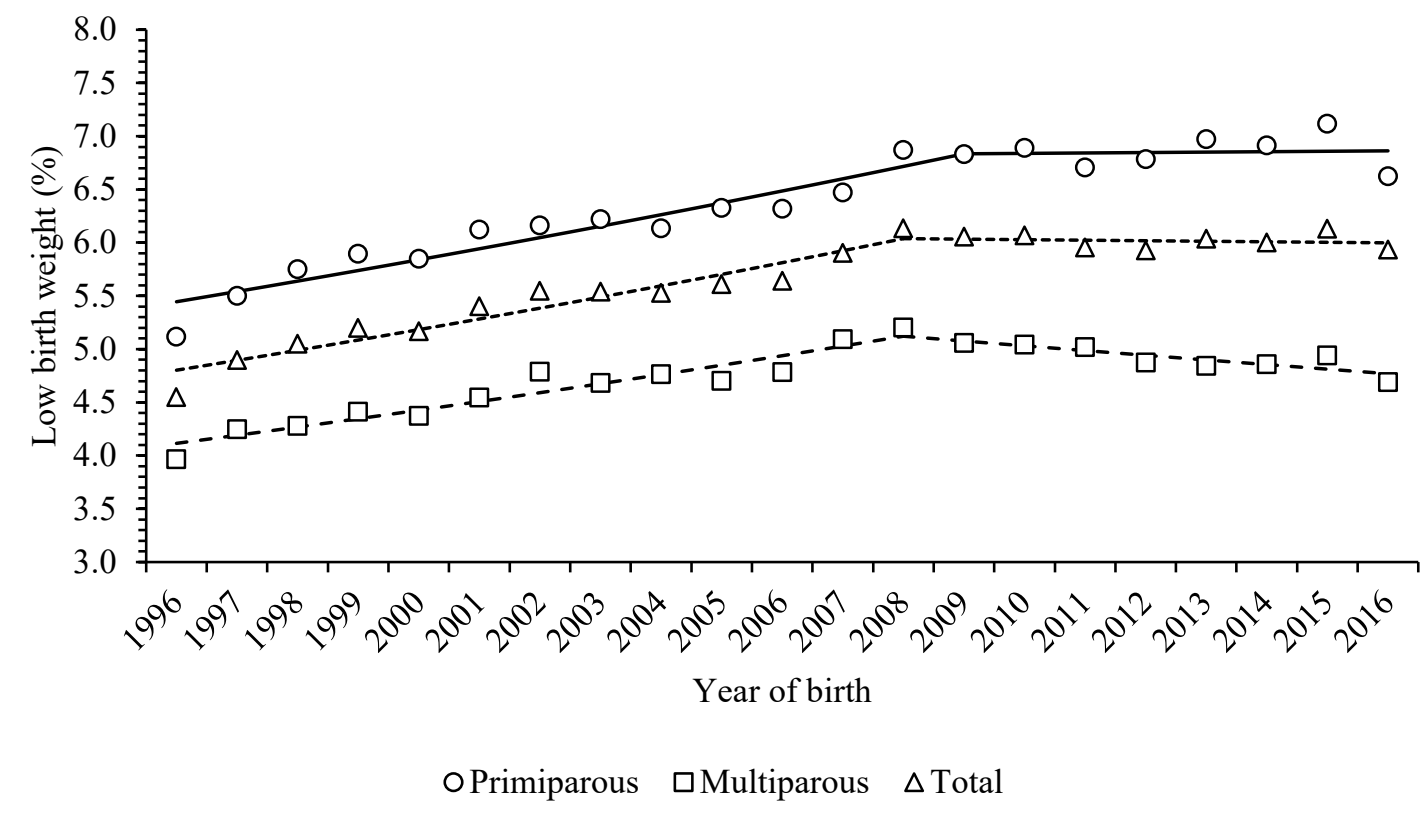


Table 1. Maternal profile and birth outcomes by parity and total. Periods $1996-2007$ and 2008-2016 (Spanish mothers, live single births, 1996-2016, NVS).

\begin{tabular}{|c|c|c|c|c|c|c|}
\hline & \multicolumn{2}{|c|}{ Primiparous } & \multicolumn{2}{|c|}{ Multiparous } & \multicolumn{2}{|c|}{ Total } \\
\hline & $1996-2007$ & $2008-2016$ & $1996-2007$ & $2008-2016$ & $1996-2007$ & $2008-2016$ \\
\hline & $\%(n)$ & $\%(n)$ & $\%(\mathrm{n})$ & $\%(n)$ & $\%(n)$ & $\%(n)$ \\
\hline \multicolumn{7}{|l|}{ Age at childbirth (years old) } \\
\hline$<20$ & $3.4(67,916)$ & $2.3(34,716)$ & $0.4(6,336)$ & $0.3(3,406)$ & $2.0(74,252)$ & $1.4(38,122)$ \\
\hline $20-24$ & $10.7(217,083)$ & $7.3(109,092)$ & $4.2(70,466)$ & $3.2(37,054)$ & $7.7(287,549)$ & $5.5(146,146)$ \\
\hline $25-29$ & $31.1(630,074)$ & $19.5(292,176)$ & $15.9(267,840)$ & $10.5(120,595)$ & $24.2(897,914)$ & $15.6(412,771)$ \\
\hline $30-34$ & $40.2(813,722)$ & $40.8(609,960)$ & $42.6(717,908)$ & $34.6(397,780)$ & $41.3(1,531,630)$ & $38.1(1,007,740)$ \\
\hline $35-39$ & $12.7(257,326)$ & $24.3(363,064)$ & $31.2(526,092)$ & $41.1(472,733)$ & $21.1(783,418)$ & $31.6(835,797)$ \\
\hline$\geq 40$ & $2.0(39,695)$ & $5.8(86,293)$ & $5.7(96,533)$ & $10.3(118,828)$ & $3.7(136,228)$ & $7.8(205,121)$ \\
\hline \multicolumn{7}{|l|}{ Maternal occupation } \\
\hline Professionals & $23.5(405,890)$ & $33.0(450,784)$ & $21.1(308,365)$ & $30.7(338,274)$ & $22.4(714,255)$ & $32.0(789,058)$ \\
\hline Administrative employees & $21.4(369,426)$ & $24.1(328,506)$ & $16.5(239,880)$ & $21.5(237,650)$ & $19.1(609,306)$ & $22.9(566,156)$ \\
\hline Service sector workers & $22.1(381,160)$ & $19.9(272,040)$ & $15.3(223,063)$ & $16.9(186,372)$ & $19.0(604,223)$ & $18.6(458,412)$ \\
\hline Qualified workers & $6.0(103,923)$ & $2.5(33,484)$ & $4.1(59,869)$ & $2.5(27,197)$ & $5.1(163,792)$ & $2.5(60,681)$ \\
\hline Unskilled workers & $1.4(24,601)$ & $6.0(81,949)$ & $1.5(22,343)$ & $6.1(6,593)$ & $1.5(46,944)$ & $6.1(149,542)$ \\
\hline Students & $1.4(24,927)$ & $2.1(28,761)$ & $0.2(29,965)$ & $0.4(4,947)$ & $0.9(27,892)$ & $1.4(33,663)$ \\
\hline Housewives & $24.1(414,971)$ & $12.4(168,491)$ & $41.3(601,689)$ & $21.9(241,333)$ & $31.9(1,016,660)$ & $16.6(409,824)$ \\
\hline \multicolumn{7}{|l|}{ Marital status } \\
\hline Married & $76.1(1,541,082)$ & $53.3(796,283)$ & $86.6(1,459,796)$ & $71.0(816,531)$ & $80.9(3,000,878)$ & $61.0(1,612,814)$ \\
\hline \multicolumn{7}{|l|}{ Parity } \\
\hline Primiparous & --- & --- & --- & --- & $54.6(2,025,816)$ & $56.5(1,495,301)$ \\
\hline \multicolumn{7}{|l|}{ Place of residence } \\
\hline Rural & $18.3(370,918)$ & $17.8(266,609)$ & $19.0(320,835)$ & $18.5(212,894)$ & $18.6(691,753)$ & $18.1(479,503)$ \\
\hline \multicolumn{7}{|l|}{ Sex of newborn } \\
\hline Male & $51.5(1,043,891)$ & $51.5(770,647)$ & $51.6(869,943)$ & $51.6(593,557)$ & $51.6(1,913,834)$ & $51.6(1,364,204)$ \\
\hline \multicolumn{7}{|l|}{ Gestational age } \\
\hline Preterm & $6.2(125,831)$ & $5.8(87,102)$ & $6.1(102,846)$ & $5.4(61,817)$ & $6.2(228,677)$ & $5.6(148,919)$ \\
\hline \multicolumn{7}{|l|}{ Birthweight } \\
\hline LBW & $6.0(121,989)$ & $6.9(102,438)$ & $4.6(76,734)$ & $5.0(57,055)$ & $5.4(198,723)$ & $6.0(159,493)$ \\
\hline \multicolumn{7}{|c|}{ 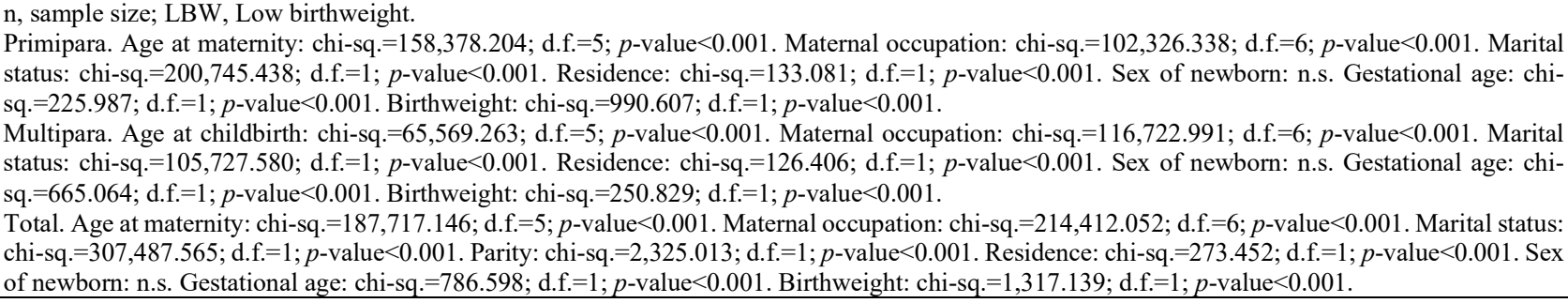 } \\
\hline
\end{tabular}


Table 1A. Prevalence of low birthweight by parity and total (Spanish mothers, live single births, 1996-2016, NVS).

\begin{tabular}{|c|c|c|c|}
\hline & Total & Primiparous & Multiparous \\
\hline & \multicolumn{3}{|c|}{$\%(\mathrm{n})$} \\
\hline 1996 & $4.55(12,662)$ & $5.12(7,225)$ & $3.96(5,437)$ \\
\hline 1997 & $4.90(14,037)$ & $5.50(8,164)$ & $4.25(5,873)$ \\
\hline 1998 & $5.05(14,421)$ & $5.75(8,587)$ & $4.28(5,834)$ \\
\hline 1999 & $5.20(15,281)$ & $5.89(9,184)$ & $4.41(6,097)$ \\
\hline 2000 & $5.17(15,866)$ & $5.85(9,684)$ & $4.37(6,182)$ \\
\hline 2001 & $5.40(16,762)$ & $6.12(10,324)$ & $4.58(6,432)$ \\
\hline 2002 & $5.55(17,419)$ & $6.16(10,712)$ & $4.79(6,707)$ \\
\hline 2003 & $5.54(18,083)$ & $6.22(11,295)$ & $4.68(6,788)$ \\
\hline 2004 & $5.53(18,310)$ & $6.14(11,334)$ & $4.76(6,976)$ \\
\hline 2005 & $5.61(18,849)$ & $6.33(11,902)$ & $4.70(6,947)$ \\
\hline 2006 & $5.64(18,791)$ & $6.32(11,787)$ & $4.78(7,004)$ \\
\hline 2007 & $5.91(18,242)$ & $6.47(11,791)$ & $5.09(6,451)$ \\
\hline 2008 & $6.13(19,540)$ & $6.87(12,210)$ & $5.20(7,330)$ \\
\hline 2009 & $6.06(18,651)$ & $6.83(11,832)$ & $5.06(6,819)$ \\
\hline 2010 & $6.07(18,563)$ & $6.89(11,684)$ & $5.04(6,879)$ \\
\hline 2011 & $5.95(17,934)$ & $6.71(11,188)$ & $5.02(6,746)$ \\
\hline 2012 & $5.93(17,311)$ & $6.78(10,941)$ & $4.87(6,370)$ \\
\hline 2013 & $6.04(16,723)$ & $6.97(10,837)$ & $4.84(5,886)$ \\
\hline 2014 & $6.00(16,897)$ & $6.91(10,819)$ & $4.86(6,078)$ \\
\hline 2015 & $6.13(17,120)$ & $7.12(10,880)$ & $4.94(6,240)$ \\
\hline 2016 & $5.94(16,754)$ & $6.62(12,047)$ & $4.69(4,707)$ \\
\hline & & &
\end{tabular}

